\title{
Comparison between rocking analysis and kinematic analysis for the dynamic out-of-plane behavior of masonry walls
}

\author{
Giresini $^{1}$, L., Fragiacomo ${ }^{1}$, M., Lourenço ${ }^{2}$, P.B. \\ ${ }^{1}$ University of Sassari lgiresini@uniss.it, fragiacomo@uniss.it \\ ${ }^{2}$ ISISE, University of Minho, Department of Civil Engineering, Guimarães, Portugal \\ pbl@civil.uminho.pt
}

\begin{abstract}
This paper provides a contribution to the rocking analysis of masonry walls by making a comparison with the kinematic analysis suggested by the Italian code. It is shown that the latter approach is generally over-conservative and therefore potentially inappropriate for historic buildings, where rehabilitation can be expensive and can affect their cultural value. The equation of motion given by the Housner formulation, corresponding to the movement of a rigid block, is here modified to account for different boundary conditions at different heights of the wall. These boundary conditions, or horizontal restrainers, can represent vaults, transverse walls or retrofitting devices such as steel tie-rods. A systemic analysis of walls having different dimensions and slenderness is performed, and the results from the Italian code and rocking analysis are compared. Finally, the improvement in the response offered by retrofitting devices is discussed in terms of reduction of amplitude ratio.
\end{abstract}

\section{KEYWORDS}

Rocking, kinematic analysis, façade, masonry, macro-element, historical buildings.

\section{INTRODUCTION}

A localized structural analysis approach using macro-elements is the most accepted tool for seismic vulnerability evaluation of historic masonry structures [1]. Indeed, damages often take place locally, due to several factors including the poor masonry mechanical properties, the presence of insufficient connections between structural parts, and the complex constructive stages that occurred over time [2]. Macro-elements, considered structurally independent from the rest of the structure, can be identified as sets of rigid blocks, whose vulnerability to a given seismic input can be possibly correlated to the acceleration that triggers motion [3]. The current Italian code [4] prescribes the use of a kinematic, linear or non-linear, analysis to verify the safety of these macro-elements. Due to its simplicity, this approach neglects relevant aspects of the motion such as the evolution of the system over time and the energy dissipation.

By contrast, dynamic analysis - namely the direct integration of the motion equation considers changes of motion and the effect of inertial forces during reversal loads such as seismic actions. The post-uplift dynamic stability is related to the effect of rotational inertia, which influences the scale effect $[5,6]$. In this formulation, the damping effect can be also easily considered. This paper provides a contribution on the opportunity to use dynamic analysis in the problem under discussion, particularly when historical buildings are analyzed. 
The first key contribution on the rocking analysis is due to Housner, whose formulation is presented in [7]. Makris and Roussos [8] studied the response of rigid blocks to pulse-type excitations, which were found to be good representations of near-source ground motions that have distinguishable long duration pulses[9, 10]. Other contributions to the topic with experimental tests were given by Doherty [11], Al Shawa et al. [12] and Sorrentino et al. [13], among others. Analytical and numerical approaches were developed by Sorrentino [14], de Felice and Giannini [15], Prieto et al. [16]. Masonry façades of churches, in particular, were studied with the discrete element method[17].

It is relevant to investigate the accuracy of the current approach presented in the Italian code[4]. Anover-conservative approach may in fact lead to expensive strengthening techniques in historical structures, which can also affect their cultural value. In addition, it is important to define the effectiveness of intervention techniques in terms of enhancement of the dynamic response. Therefore, this paper deals with both these aspects, namely the effect of different boundary conditions in the Housner block, and the comparison between rocking analysis and kinematic analysis, as proposed by the Italian code. After a first insight in the Housner formulation, the validation of a Matlab code written to solve the dynamic problem is presented. Afterwards, systemic analyses are performed to show possible inconsistencies between the integration of the equation of motion and the kinematic analysis. The effect of strengthening techniques is included by adding the appropriate term in the equation of motion. A non-linear analysis of a church façade connected to a vault and a steel tie-rod is also presented and critically discussed. Finally, additional analyses are performed to evaluate the improvement of the dynamic response in terms of reduction of amplitude ratios induced by horizontal restrainers.

\section{HOUSNER FORMULATION}

The Housner model [7] is the basis of the classical theory of rocking analysis. This author studied the 2D problem of a rigid body subjected to free vibrations, constant and sinusoidal acceleration, and earthquake motion. The single-degree-of-freedom (SDOF) block is a rigid prism with longitudinal rectangular cross-section, rocking about the two corners $\mathrm{O}$ and $\mathrm{O}^{\prime}$ (Fig. 1) and supported by a flat rigid base. Neither bouncing (namely, no stocky elements) nor sliding are considered [18].

The significant geometric parameters of the block are: (1) the slenderness ratio $\alpha$, given by the inverse of the tangent of the base to height ratio $b / h$, where $2 b$ is the thickness and $2 h$ is the height of the block; (2) the length of the semi-diagonal $R$ of the block, which defines the block size.

(a)

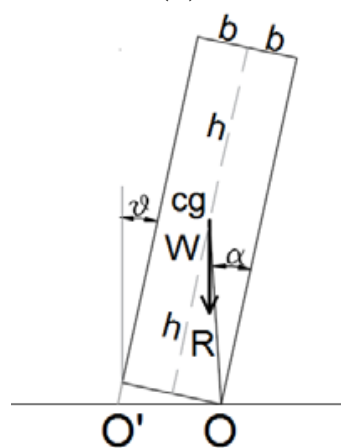

(b)

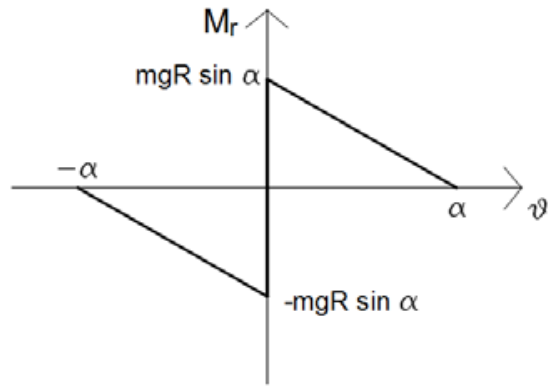

Fig. 1 - The rectangular free-standing rocking block, adapted from[7] (a) and the corresponding moment-rotation diagram (b) 
Considering the rotation $\vartheta$ ( $>0$ if counter-clockwise) as a Lagrangian coordinate, the equation of motion takes the form:

$$
I_{0} \ddot{\vartheta}+\operatorname{sgn}(\vartheta) m g R \sin (\alpha-\operatorname{sgn}(\vartheta) \vartheta)-m g \ddot{u}_{g} R \cos (\alpha-\operatorname{sgn}(\vartheta) \vartheta)=0
$$

where $I_{0}$ is the inertia moment, $m$ is the mass and $\ddot{u}_{g}$ is the acceleration time-history (in $g$ )of the mass, if any.Eq.(1)can be modified for homogeneous prismatic blocks as follows:

$$
\ddot{\vartheta}+\operatorname{sgn}(\vartheta) p^{2} \sin (\alpha-\operatorname{sgn}(\vartheta) \vartheta)-p^{2} \ddot{u}_{g} \cos (\alpha-\operatorname{sgn}(\vartheta) \vartheta)=0
$$

Here, $p$ signifies the frequency parameter, equal to $\sqrt{\frac{3 g}{4 R}}$. The dynamic equivalence between a free-standing rocking frame and a solitary rocking column was first shown by Makris and Vassiliou [19]. DeJong and Dimitrakopoulos extended their results for the asymmetric rocking frame and the hinging masonry arch [20], defining proper values of $p$ in Eq. (2).

The proposed model is a simplification of the actual behavior, due to the strong nonlinearities characterizing the problem concerning the system stiffness, which depends on boundary conditions, initial imperfections, material strength or geometry [14]. Additionally, damping effects are complex to describe and generally valid only for specific masonry types experimentally tested. During rocking, dissipation of energy occurs at the impact of the block on the base. The energy loss may be calculated by the variation of kinetic energy before and after the impact. Experimental tests found in literature correlated the energy loss to a restitution coefficient, firstly introduced by Aslam et al.[21], defined as a ratio of angular velocities after and before the impact. In the Housner formulation, the theoretical restitution coefficient edepends upon the slenderness ratio $\alpha$ :

$$
e=1-\frac{3}{2} \sin ^{2} \alpha
$$

Experimental tests were performed to identify the values of the restitution coefficients for different unreinforced masonry (URM) specimens of various material and slenderness ratios $[11,13,22]$.The restitution coefficient given by Eq. (3)was found to be higher than the experimental one in most cases, as the real case does not fully comply with the underlying hypotheses. By recognizing the difficulty in correlating $e$ with the maximum rotation before impact or with the semiperiod, Sorrentino [14] suggested a value of eequal to $90 \%$ of the theoretical value.

\section{ANALYSIS OF SDOF BLOCKS}

\subsection{Software code validation}

A Matlab code was purposely developed to investigate the dynamic response of rigid blocks according to the Housner's approach[7]. The code validation for the Housner model was performed comparing results with those obtained by Makris and Kostantinidis [23] and by Sorrentino [14]. The rocking motion is described by the integration of Eq. (1), where the Lagrangian coordinate is the rotation $\vartheta$. The code was implemented in Matlab R2013 [24] adopting the ODE45 solver, which uses the 4th-5th order Runge-Kutta integration technique [25]. 
Damping effects were included by considering the restitution coefficient $e$ depending on the slenderness $\alpha$ according to Eq. (3). At each impact $(\vartheta=0)$, the velocity at the previous step is automatically decreased by a factor equal to the restitution coefficient $e$. The reduction of velocity numerically occurs by means of an event-identification function, which stops the integration when the condition $\vartheta=0$ has been attained. If the motion is one-sided, for instance in the case of a façade restrained by transverse walls, the rebound is expressed by an additional damping $r_{\mathrm{f}}$ and a change in velocity sign [26]. $r_{\mathrm{f}}$ is the coefficient of restitution reduction factor, ranging between 0 and 1 , and has a great impact on the overturning rate. The instability threshold is assumed when $\vartheta=\pi / 2$, assuming that the block can "survive" once the rotation $\vartheta$ reaches and overcomes $\alpha$ [27]. As a first comparison, a free vibration problem was considered, with initial condition $\vartheta_{0} / \alpha=0.9$, showing an excellent agreement (Fig. 2a).

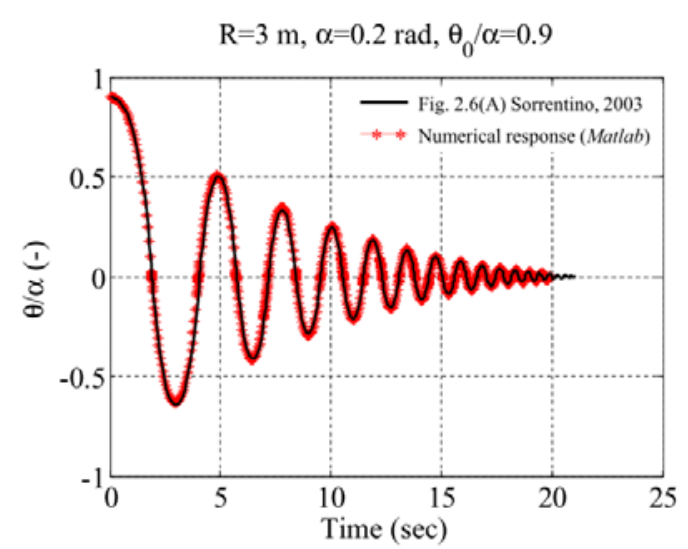

(a)

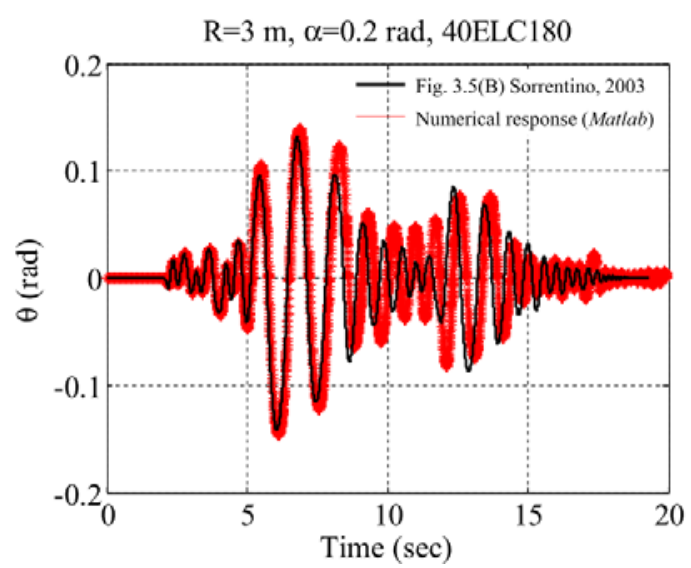

(b)

Fig. 2 - Comparison between the proposed Matlab code results and Sorrentino [14]: free vibration of the block with given initial rotation (a) and block subjected to El Centro acceleration time history (b)

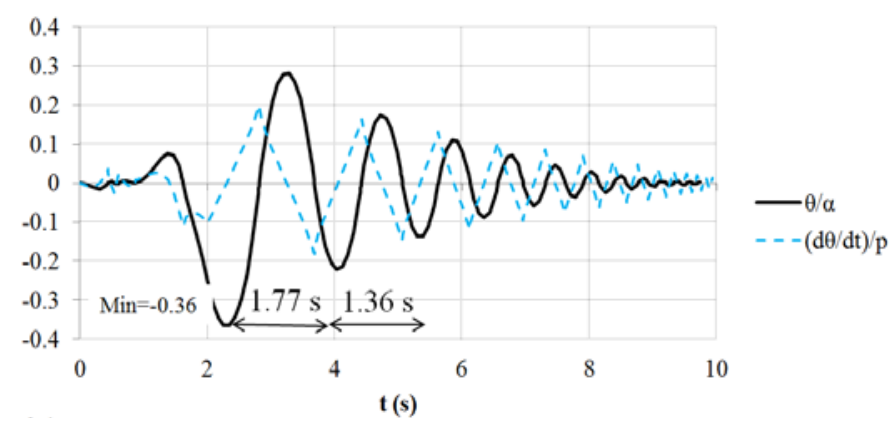

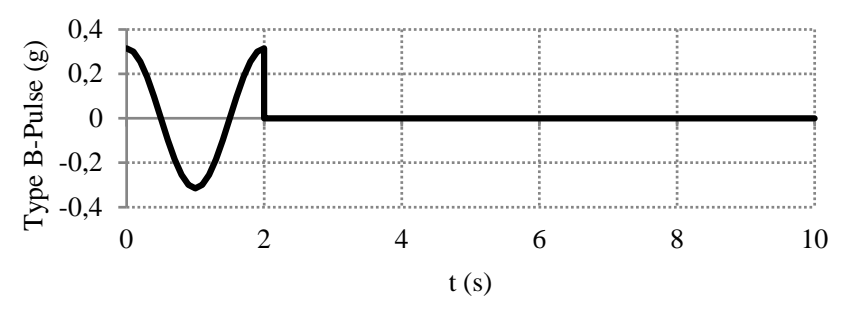

(a)

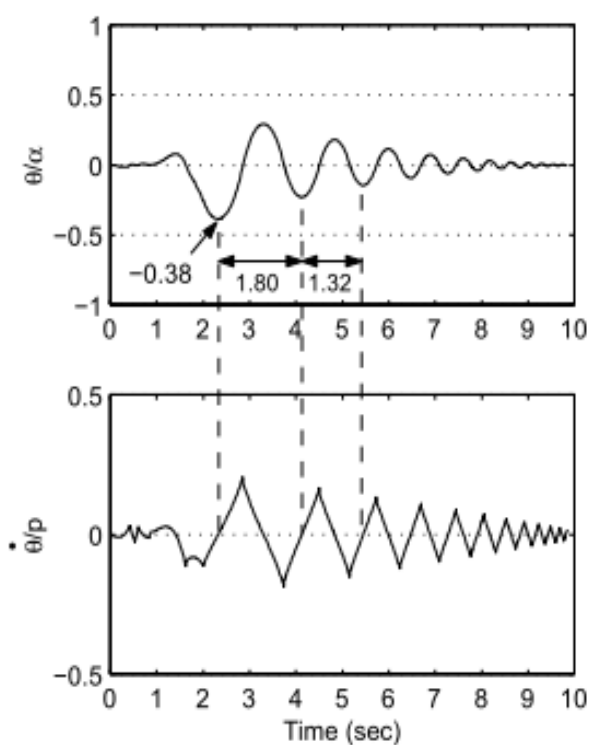

(b)

Fig. 3-Comparison between Housner model response to type-B cosine pulse (amplitude $0.310 \mathrm{~g}$, a) as computed using the proposed Matlab software and that calculated by Makris (b) (fig. 4.1 in [23])

In addition, forced vibrations were considered, analyzing the response of a block with $R=$ $3 \mathrm{~m}, p=1.566 \mathrm{rad} / \mathrm{sec}$ and $\alpha=0.2 \mathrm{rad}$ subjected to the well-known record of El Centro 
earthquake ground motion (Imperial Valley 5/19/40 04:39, El Centro array 9, 180). In this calculations, values of absolute tolerance (AbsTol) and relative tolerance (RelTol) defined in [24] are set to 1E-6. A good agreement is again obtained (Fig. 2b). In addition, the proposed software was validated on the example provided by Makris and Kostantinidis [23] with $R=$ $1.839 \mathrm{~m}, \alpha=0.262 \mathrm{rad}$, and $p=2.0 \mathrm{rad} / \mathrm{sec}$. The excitation applied to the system is a cosine pulse with duration $T_{p}=2 \mathrm{sec}$. After the pulse, the force vanishes and the integration continues up to 10 seconds to analyze the vibration effects. The responses of the rocking block to the cosine pulse, depicted in Fig. 3, are in close agreement.

\subsection{The altar of the Annunziata church in Italy: force -displacement based approach vs dynamic transient analysis}

Aiming at discussing the accuracy of the different structural analyses approaches in engineering applications, the Matlab code is applied to the altar of the Beata Vergine Annunziata church (Reggiolo, Emilia Romagna, Italy), which experienced a crack all along its base during the 2012 earthquake (Fig. 4) and, therefore, it probably rocked during motion (without overturning). The altar has a prismatic shape and therefore can be easily assimilated to the Housner block.

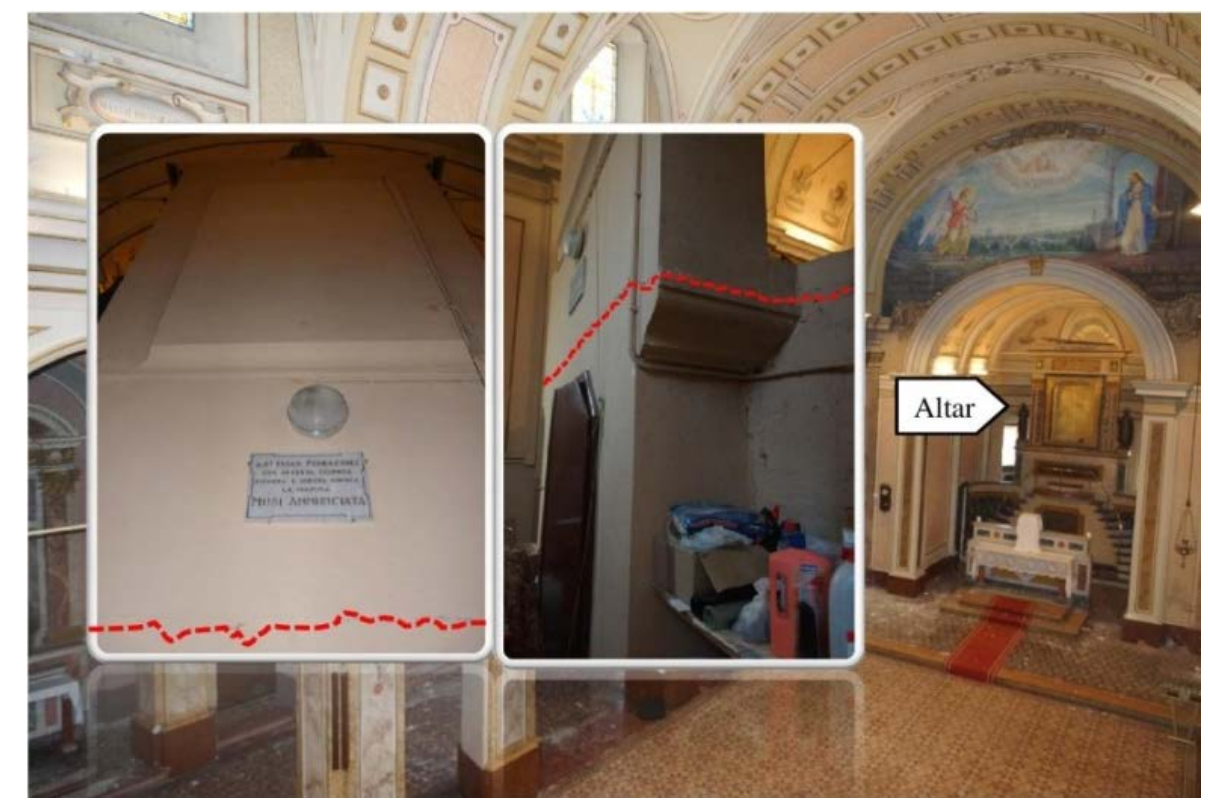

Fig. 4 - Altar in the BeataVergine Annunziata church

The altar has dimensions of 2.26 (higher part) to $2.66 \mathrm{~m}$ (lower part) at the base, total height of $6.00 \mathrm{~m}$ and a thickness between 0.47 and $0.51 \mathrm{~m}$ (Fig. 5). An equivalent prism was determined assuming a base length of $2.40 \mathrm{~m}$ and considering the actual height of $2.96 \mathrm{~m}$ (from the top to the crack position).An equivalent thickness of $0.487 \mathrm{~m}$ was then calculated. The equivalent block has therefore $R=1.499 \mathrm{~m}$ and $\alpha=0.163 \mathrm{rad}$ (9.34 degrees). The block is then subjected to two near fault natural seismic records, Mirandola (MRN) and Moglia (MOG), occurred during the earthquake on May 29², 2012.

If the vulnerability assessment is done according to the Italian code [28], the beginning of motion is correctly predicted (Fig. 6), namely the Damage Limit State (DLS) is not satisfied (indeed the crack formed as expected). The second requirement concerning the Ultimate Limit State (ULS), assuming the base of the block at $2.96 \mathrm{~m}$ as actually is, is not satisfied either. 

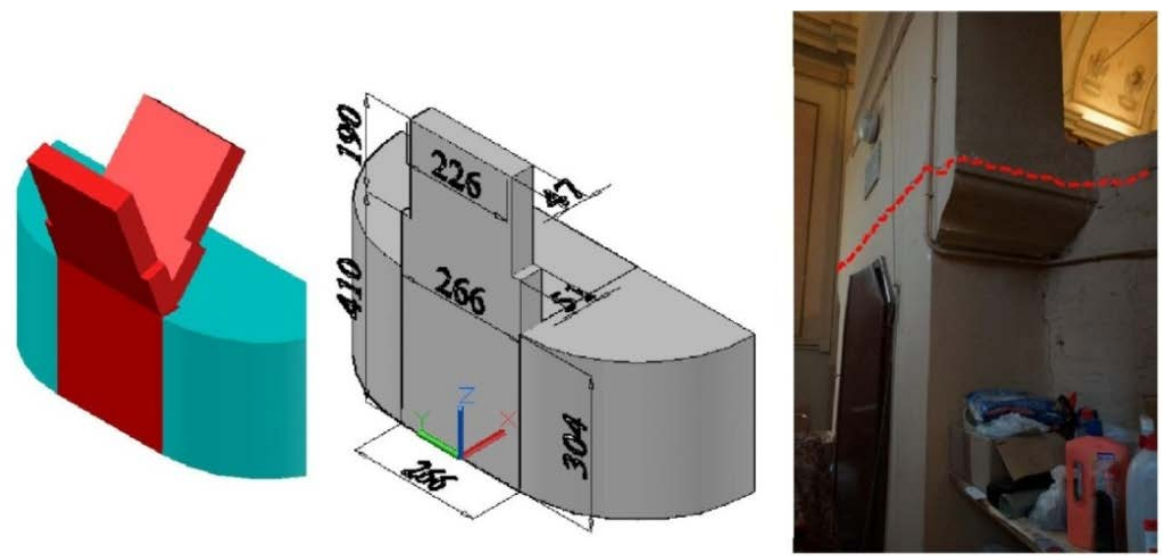

Fig. 5 - Dimensions (cm) and rocking motion of the altar in B. V. Annunziata church

Thus, according to the Italian code procedure, the block would collapse. The value of the displacement demand $S_{d e}$ was taken for $T_{s}=T_{1}=1.09 \mathrm{~s}$, corresponding to the secant period obtained from the capacity curve, since the altar is independent from the first vibration period of the church. The secant (also called "effective") period can also be used for predicting the response of bilinear systems and rocking systems with negative stiffness, as proposed by Makris and Kampas [29]. The altar response to MRN and MOG records, assuming $e$ from Eq. (3),is displayed in Fig. 7. The analysis was carried out by changing the polarity in sign of the acceleration time-histories, since the response can differ when the peak ground acceleration is assumed to occur from left to right and from right to left (Fig. 5) [26]. The maximum amplitude ratio is only about $7 \%$ and $18 \%$ respectively of the slenderness ratio $\alpha$, namely the altar was not particularly vulnerable to this action. According to this analysis, the block survives both excitations. The current normative approach is therefore too conservative to assess the seismic vulnerability of the altar.

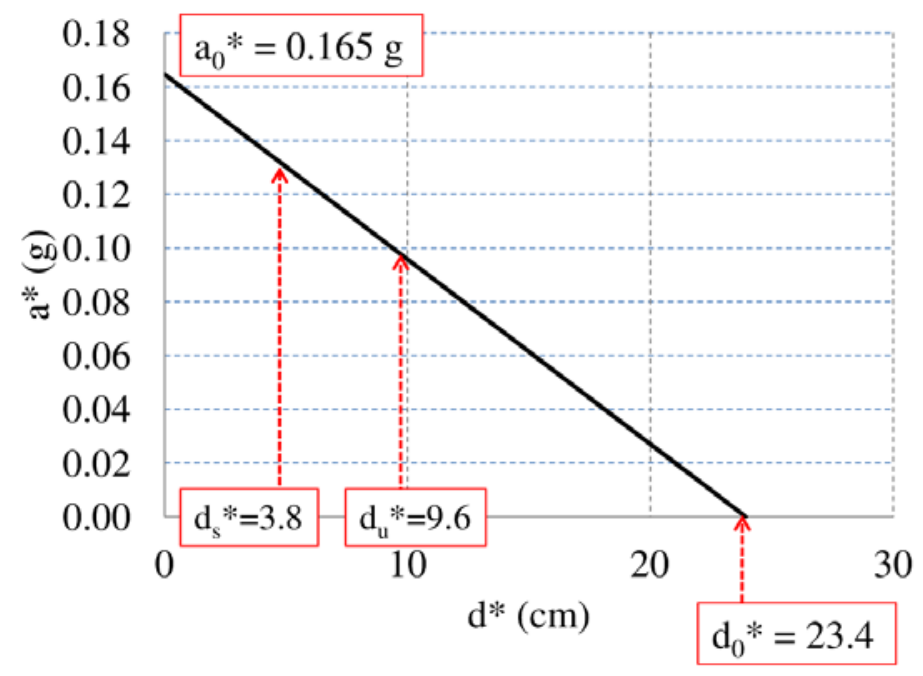

DLS

$\mathrm{a}_{0} * \leq \mathrm{a}_{\mathrm{g}, \mathrm{MOG}} \mathrm{S}=0.353 \mathrm{~g}$ $\mathrm{a}_{0} * \geq \mathrm{S}_{\mathrm{e}, \mathrm{MOG}}\left(\mathrm{T}_{1}\right) \psi \gamma=0.082 \mathrm{~g}$

\section{ULS}

$\mathrm{d}_{\mathrm{u}} * \geq \mathrm{S}_{\mathrm{de}, \mathrm{MOG}}\left(\mathrm{T}_{\mathrm{s}}\right)=4.7 \mathrm{~cm}$

(on the ground)

$\mathrm{d}_{\mathrm{u}} * \leq \mathrm{S}_{\mathrm{de}, \mathrm{MOG}}\left(\mathrm{T}_{1}\right) \psi \gamma \mathrm{f}\left(\mathrm{T}_{\mathrm{s}} / \mathrm{T}_{1}\right)$

$$
=16.82 \mathrm{~cm}
$$

(at height $Z=3.04 \mathrm{~m}$ )

Fig. 6 - Altar capacity curve according to the Italian code[28] considering MRN and MOG records, $\gamma=1, T_{s}=T_{1}=1.09 \mathrm{~s}, \psi=0.51$ 

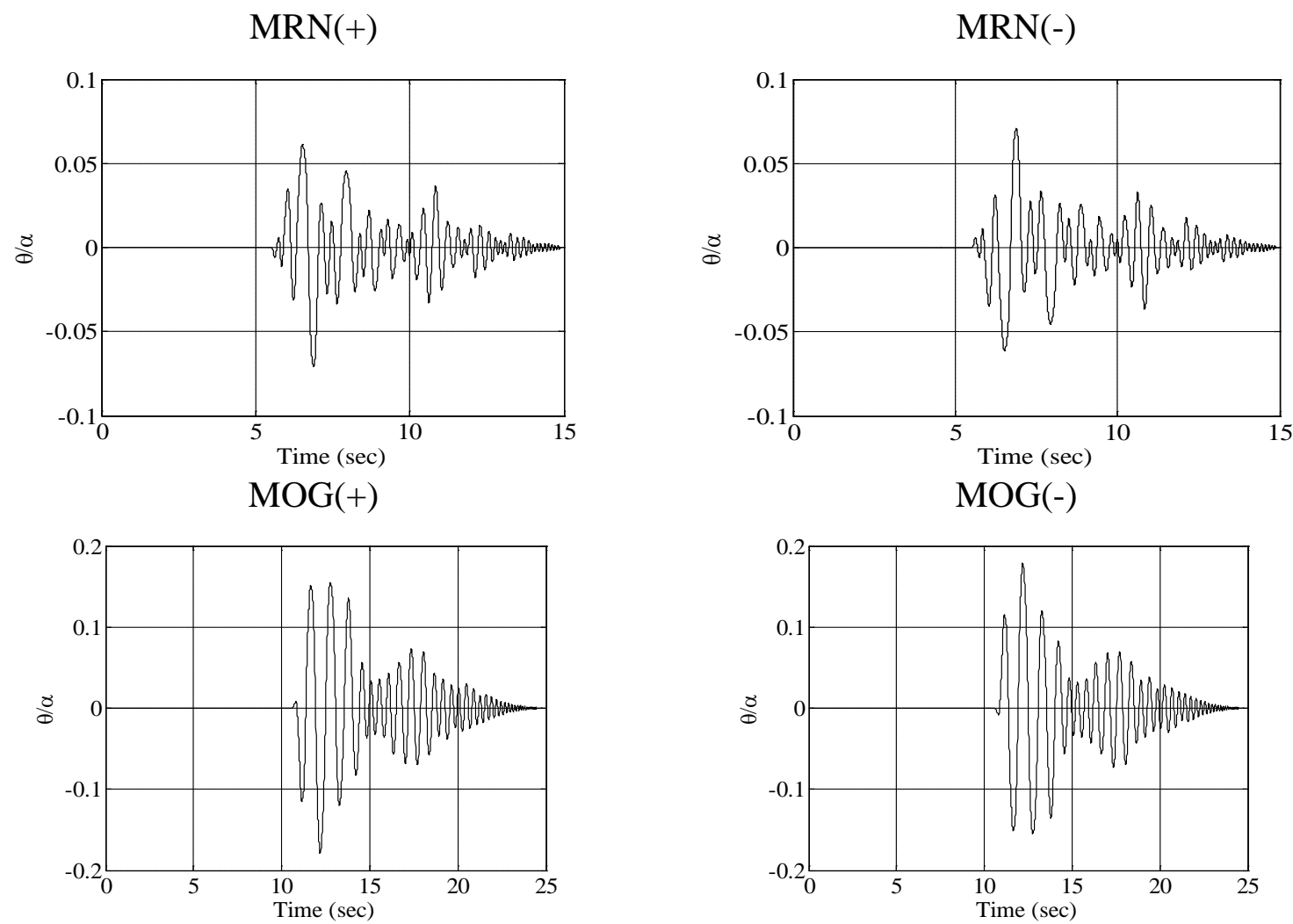

Fig. 7 - Dynamic response of the altar under MRN and MOG records (both polarities and restitution coefficient from Eq. (3))

\subsection{Systemic analysis for different spectra and different recorded earthquakes}

Masonry walls, which may be façades or elements similar to blocks, have been studied considering different rocking spectra. The aim is to compare more in detail the results obtained with the rocking analysis and with the kinematic non-linear analysis as proposed by the Italian code. The assumed simplifications are, again, that: (i) the block rotates around its corner (infinite compressive strength, but a proper reduction of $R$ can account for a finite value of compressive strength); (ii) the motion is out-of-plane in $2 \mathrm{D}$; and (iii) neither bouncing nor sliding occur. Moreover, no geometrical imperfections are considered, thus a bilinear curve is assumed for the force-displacement relationship [11]. The lack of a systematic correlation between the response and geometrical imperfections suggests the assumption of no imperfections [26].

Four walls sizes $R=1.5,3.5,7,10 \mathrm{~m}$ and four values of slenderness ratio $\alpha=b / h$ between 0.05 and 0.25 have been considered. Note that, according to [30], the usual relation in historic buildings is about $1 / 7$ or 0.14 , whereas the slenderness is limited by Eurocode 6 [31] to 1/27 for walls supported at the top or bottom (therefore $1 / 13.5=0.08$ for cantilever walls). The variation in the $R$ value addresses the size effect. In addition, the restitution coefficient has been taken equal to $90 \%$ of the theoretical one given by Eq.(2).The considered acceleration records are reported in Table 1 [32, 33]. They have magnitude MW between 6.0 and 7.1, three of them (MRN, AQV and CAPE M) are far field (distance from the source more than $15 \mathrm{~km}$ ), while the others are near field records.

The results of the analysis are displayed in Fig. 8. If the code procedure is applied, with $R$ constant, the secant period $T_{s}$ is the same by changing $\alpha . T_{s}$ increases if $R$ increases, when $\alpha$ is kept constant. Thus, if the displacement demand increases when the equivalent period 
increases, the verifications for the same $\alpha$ values are generally less severe for greater $R$ (Fig. 8). The same occurs if the rocking analysis is performed, due to the scale effect [7,34], which is significant for high amplitude excitations. Therefore, a scale effect emerges also in the kinematic approach.

\begin{tabular}{|c|c|c|c|c|c|c|c|c|c|c|c|}
\hline Eventname & Date & MW & Station & $\begin{array}{c}\text { Soiltype } \\
\text { (EC) }\end{array}$ & $\begin{array}{c}\text { Comp } \\
.\end{array}$ & $\begin{array}{c}\text { PGA } \\
(\mathrm{g}) \\
\end{array}$ & Network & $\begin{array}{c}\text { Depth } \\
(\mathrm{km})\end{array}$ & $\begin{array}{l}\text { PGV } \\
(\mathrm{m} / \mathrm{s}) \\
\end{array}$ & $\begin{array}{l}\text { PGD } \\
(\mathrm{cm})\end{array}$ & $\begin{array}{l}\text { Repi } \\
(\mathrm{km})\end{array}$ \\
\hline NVL & 05-29-2012 & 6.0 & Novellara & $\mathrm{C}$ & E-W & 0.055 & I & 10.2 & 0.0257 & 7.68 & 28.0 \\
\hline MRN & 05-29-2012 & 6.0 & Mirandola & $\mathrm{C}$ & E-W & 0.212 & I & 10.2 & 0.2851 & 9.14 & 4.1 \\
\hline MOG0 & 05-29-2012 & 6.0 & Moglia & $\mathrm{C}^{*}$ & E-W & 0.236 & I & 10.2 & 0.266 & 3.75 & 16.4 \\
\hline CAPEMEND & 04-25-1992 & 7.1 & $\begin{array}{c}\text { Cape } \\
\text { Mendocino }\end{array}$ & - & 0 & 1.346 & $\mathrm{U}$ & 9.6 & 1.274 & 41 & 10.4 \\
\hline $\mathrm{AQV}$ & 06-04-2009 & 6.3 & $\begin{array}{c}\text { L'Aquila-V } \\
\text { Aterno }\end{array}$ & B & E-W & 0.657 & I & 8.3 & 0.4 & 6.79 & 5.1 \\
\hline
\end{tabular}

Table 1 - Acceleration time histories in parametric rocking analysis. Network: I=IT-RANDPC[32], U=USGS[33]

The capacity is lower than the demand for records with larger PGV, which is confirmed to be a critical parameter to measure the destructive potential of an earthquake record [34], even if the block is treated as an equivalent oscillator. Indeed, for instance if $\alpha=0.10 \mathrm{radand} R=$ $3.5 \mathrm{~m}$, the block collapses with MRN record, which has a PGA lower than MOG, but higher PGV (Table 1).
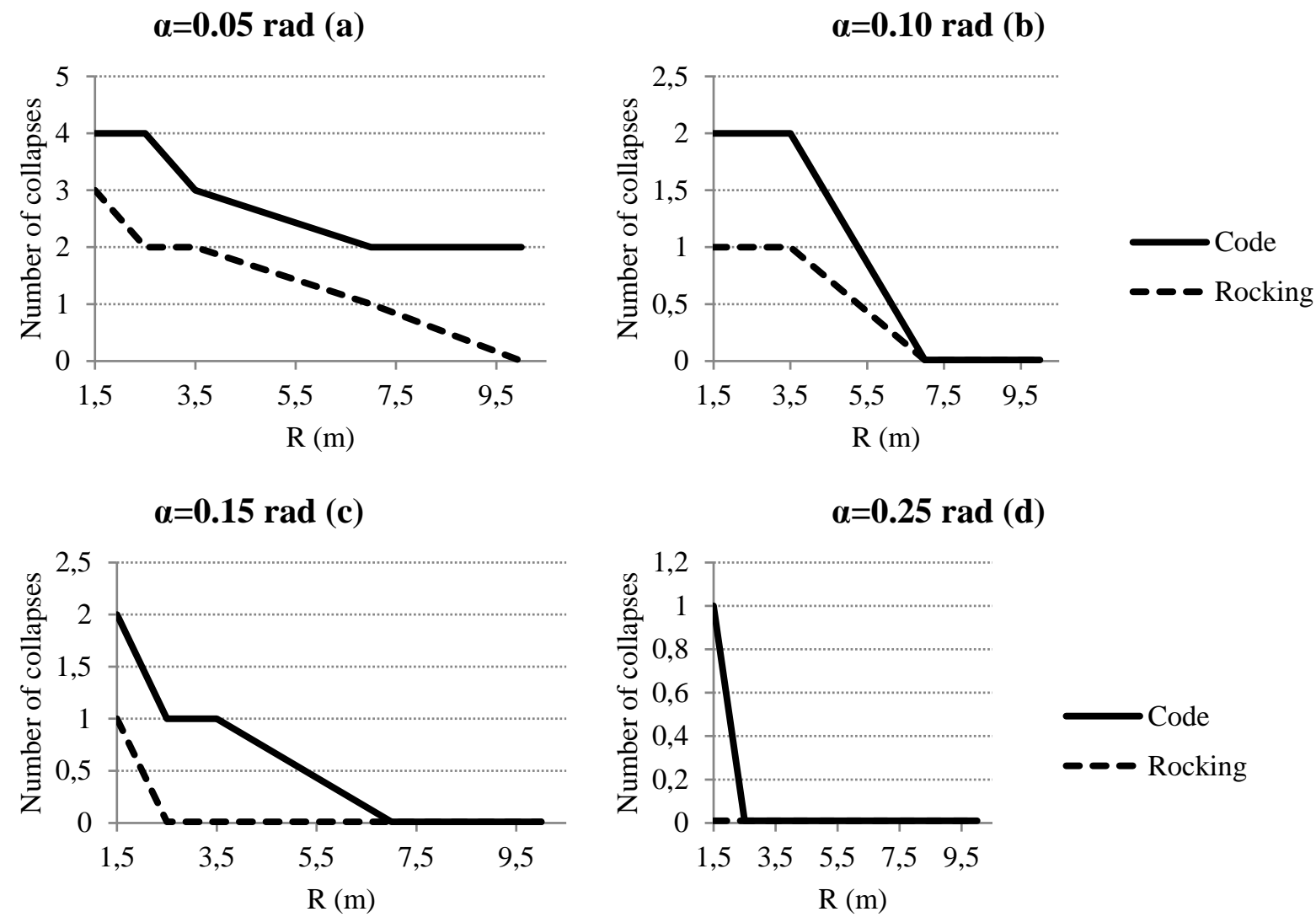

Fig. 8 - Number of collapses considering the code approach and the rocking analysis, for blocks with $R$ varying from 1.5 to $10 \mathrm{~m}$ and $\alpha$ between 0.05 and 0.25 for all the considered seismic records 
Nevertheless, if MOG is considered, the block survives the earthquake. The same occurs for MRN and MOG in the rocking analysis, for $\alpha=0.05 \mathrm{radand} R=3.5 \mathrm{~m}$. The verifications not satisfied in the code approach are often verified in the rocking analysis; the opposite never happens. In the 100 analysis performed, there are in total 14 inconsistencies, namely cases which are safe with rocking analysis and unsafe with the normative approach. 26blocks collapse with the code approach, therefore the normative method is conservative in about $14 / 26=54 \%$ of the cases in which collapse occurs.

\section{ANALYSIS OF DYNAMIC RESPONSE FOR DIFFERENT BOUNDARY CONDITIONS}

\subsection{Modification of the equation of motion}

The rocking analysis of rigid blocks is now modified by adding a spring with stiffness $K$ to represent an element with stabilizing effect, such as strengthening devices (tie-rods), transverse walls, vaults, etc. The equation of motion for a block subject to external excitation (Eq. (1)) now reads:

$$
\begin{gathered}
I_{0} \ddot{\vartheta}+\operatorname{sgn}(\vartheta) m g R \sin (\alpha-\operatorname{sgn}(\vartheta) \vartheta)+ \\
+\operatorname{sgn}(\vartheta) 4 K R^{2} \cos (\alpha-\operatorname{sgn}(\vartheta) \vartheta)[\sin \alpha-\sin (\alpha-\operatorname{sgn}(\vartheta) \vartheta)] \\
-m g \ddot{u}_{g} R \cos (\alpha-\operatorname{sgn}(\vartheta) \vartheta)=0
\end{gathered}
$$

The additional term dependent on $K$ is obtained first by computing the differential displacement (in a deformed configuration) of a given point in the horizontal direction, see Fig. 9a. If the spring is at the top, $2 R$ is the position vector describing motion (radius vector). For the sake of simplicity, the rotation angle $\vartheta$ and its differential $\delta \vartheta$ are assumed positive if counter-clockwise. By starting from a deformed configuration (initial rotation angle equal to $\vartheta$ ), an infinitesimal rotation $\delta \vartheta$ determines the horizontal displacement:

$$
\delta Z=2 \mathrm{R} \cos (\alpha-\operatorname{sgn}(\vartheta) \vartheta) \sin \delta \vartheta
$$

The definite integral over the interval $[0, \bar{\vartheta}]$ (where $\bar{\vartheta}$ is a fixed current rotation) is given by:

$$
Z=2 \mathrm{R}[\sin \alpha-\sin (\alpha-\bar{\vartheta})]
$$

The virtual work principle has to be used to include the term dependent on $K$ into Eq. (1). The virtual work made by the spring with stiffness $K$ is calculated by imposing a virtual differential displacement with respect to the virtual rotation angle $\delta \vartheta$. By using Eqs. (5)and(6), the virtual work can be expressed as follows:

$$
\begin{aligned}
& \delta W=K Z \delta Z=-\operatorname{sgn}(\vartheta) 4 K R^{2} \cos (\alpha-\operatorname{sgn}(\vartheta) \vartheta)[\sin \alpha \\
& -\sin (\alpha-\operatorname{sgn}(\vartheta) \vartheta)] \sin \delta \vartheta
\end{aligned}
$$

Assuming the linearization of the trigonometric term dependent on the virtual rotation angle, the derivative of the work $W$ with respect to $\vartheta$ is therefore given by:

$$
\frac{\partial W}{\partial \vartheta}=K Z \delta Z=-\operatorname{sgn}(\vartheta) 4 K R^{2} \cos (\alpha-\operatorname{sgn}(\vartheta) \vartheta)[\sin \alpha-\sin (\alpha-\operatorname{sgn}(\vartheta) \vartheta)]
$$


which, changed in sign, gives the potential energy to include in the Euler-Lagrange equation, leading to Eq. (4). It is worth noting that this operation does not imply a linearization of the equation of motion, but only a linearization of the virtual rotation angle.
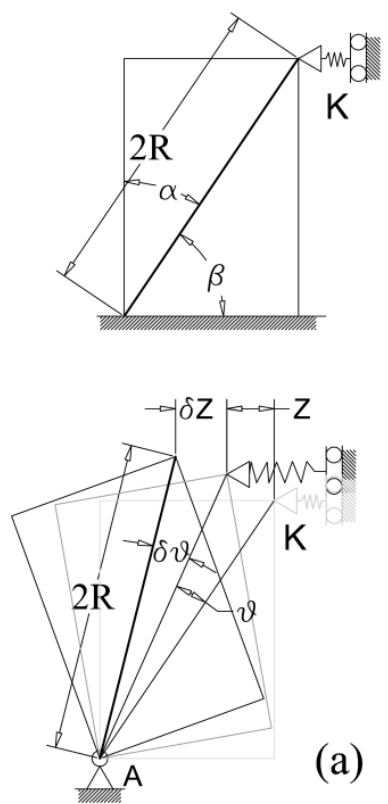
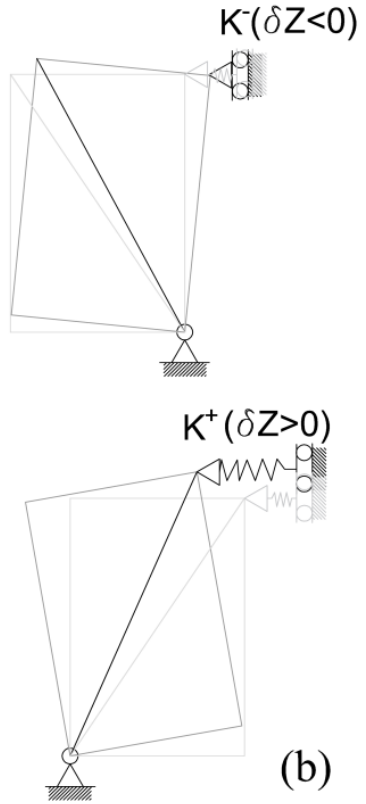
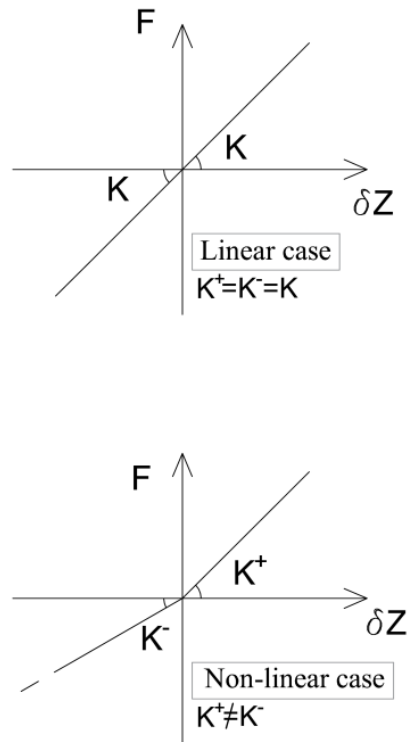

(c)

Fig. 9 - Horizontal virtual displacement $Z$ of the point where the stiffness $K$ is applied (a), stiffness sign assumption(b) and spring constitutive law (c)

The global stiffness of the system shown in Fig. 9 is negative or positive depending on the value of the horizontal restrainer stiffness $K$, on the slenderness $\alpha$ and on the semi-diagonal $R$. The influence of these parameters on the initially negative stiffness of the system, shown in Fig. 1b, is discussed in $\S 4.3$.

Fig. 9b depicts the stiffness sign convention included in the Matlab code when the nonlinear case is considered. In the linear problem, the stiffness $K$ is the same whatever the rotation sign is, while in the nonlinear case the $K$ value changes depending on whether positive (counterclockwise adopting the Housner's convention) or negative rotation occurs (Fig. 9c). The nonlinear case allows consideration of practical cases such as the presence of a transverse wall for positive rotations and the presence of a tie-rod for negative rotations.

\subsection{Non-linear case study: church façade connected to a vault and a steel tie-rod}

Masonry façades in rocking analysis are generally treated as connected to transverse wall having infinite stiffness [12, 34]. The rebound effect offered by transverse walls can be numerically considered as a change in sign of the velocity immediately after impact and possibly as an additional damping. A case study in which a finite value of stiffness is considered is discussed next, representing the situation of a church façade connected to a vault and steel tie-rod (Fig. 10). The church is the again the Beata Vergine Annunziata (Reggiolo, Italy), struck by Emilia Romagna earthquake in 2012. A crack formed at the top of the façade but no collapse occurred. The different value of stiffness when the block rotation is counterclockwise (negative) and clockwise (positive) is automatically included in the equation integration depending on the rotation angle sign. 
The equivalent stiffness of the vault is determined considering the vault as an equivalent truss, whose stiffness can be calculated in longitudinal, transverse and diagonal directions [35]. In this case, the only equivalent stiffness of interest is that in longitudinal direction. For the sake of simplicity, its initial value is considered, $K_{v}=4 E 6 \mathrm{~N} / \mathrm{m}$, even though this value suddenly drops to zero for displacements of the vault supports of the order of the millimeter. The assumed features of the system are: (a) façade with self-weight $1755 \mathrm{kN}$ and $R=5.04 \mathrm{~m}$; (b) groin vault with plane length $L=3.00 \mathrm{~m}$, rise to length ratio $f / L=0.10$, and thicknesst $=$ $6 \mathrm{~cm}$. The vault position is defined by a radius vector $R_{\text {vault }}=7.00 \mathrm{~m}$ and $\alpha_{\text {vault }}=$ $0.072 \mathrm{rad}$; (c) steel tie-rod with $20 \mathrm{~mm}$ diameter, $3.00 \mathrm{mlength}$, resulting in $K_{\text {tie }}=$ $22.0 E 6 \mathrm{~N} / \mathrm{m}$. It is assumed that the position of the spring with its stiffness is the same as the spring representing the groin vault $\left(R_{\text {vault }}=R_{\text {tie }}\right.$ and $\left.\alpha_{\text {vault }}=\alpha_{\text {tie }}\right)$.
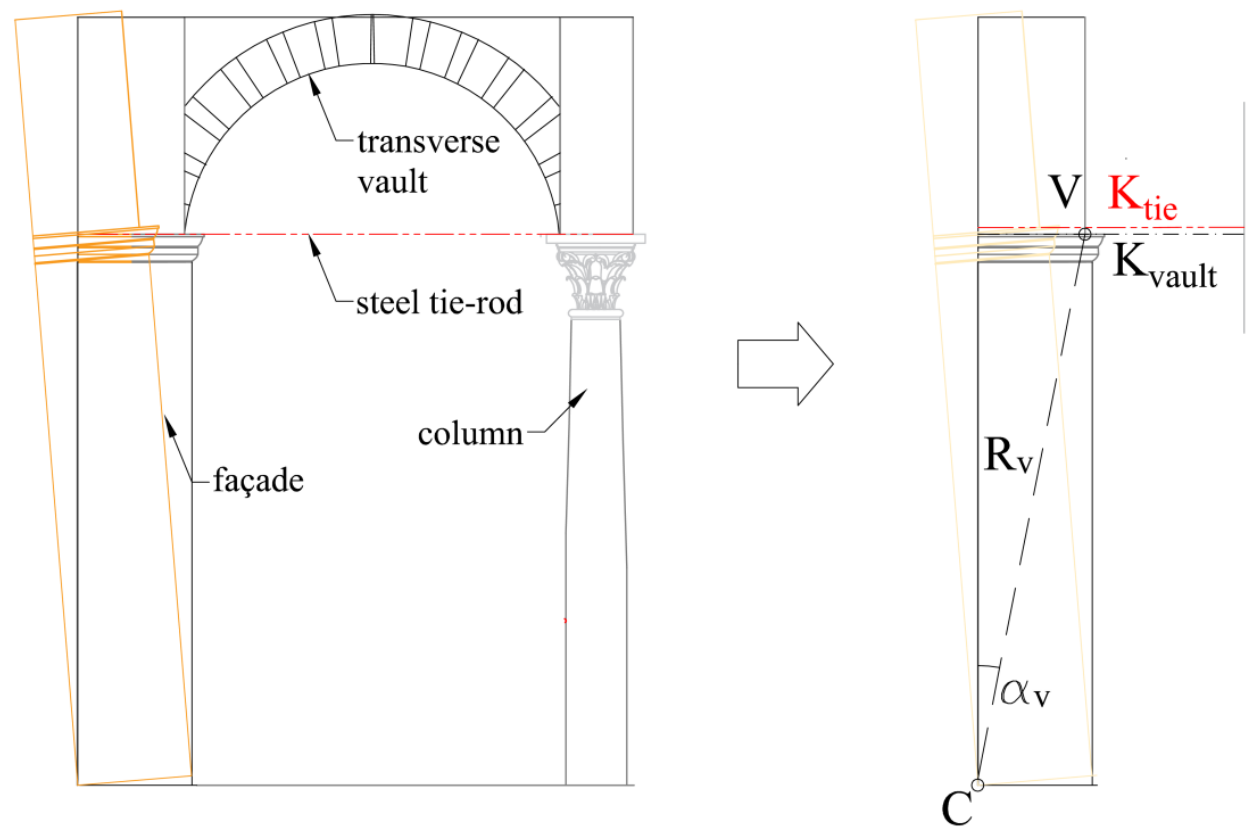

Fig. 10 - Façade of the Beata Vergine Annunziata church (Reggiolo, Emilia Romagna, Italy) connected to the vault of the lateral nave and to a steel tie: rocking scheme with corresponding equivalent stiffness

The analysis is performed considering the rebound effect proposed in [34], with the different boundary conditions of: (i) only the vault; (ii) both the vault and the steel tie-rod. The most severe results (considering the maximum amplitude ratio changing the record polarity) are reported in Fig. 11. It can be seen that by neglecting additional damping (a) could provide too conservative results, since the block overturns. Nevertheless, additional damping (b) avoids the block collapse. With the proposed software code, without the stabilizing effect of the tierod (c) the maximum amplitude ratio (absolute value) is higher than in case (b), even though the stiffness is a finite value calculated taking into account the vault in the lateral nave. If an additional steel tie rod is used, the maximum amplitude ratio is decreased from 0.6 to 0.1 (c), showing a good improvement even though the block can survive also with $K_{\text {tie }}=0$.

This analysis can be considered as an alternative to that proposed in [34], namely with the rebound effect, where the additional damping value is complex to establish. In the proposed analysis, the stiffness is calculated by taking into account the actual configuration of the connected vault and therefore a finite value of $K$ is used. It is noted that the church longitudinal walls $(0.40 \mathrm{~m}$ thick) at the sides of the façade, about $20 \mathrm{~m}$ wide, have been conservatively ignored in the evaluation of $K$. 

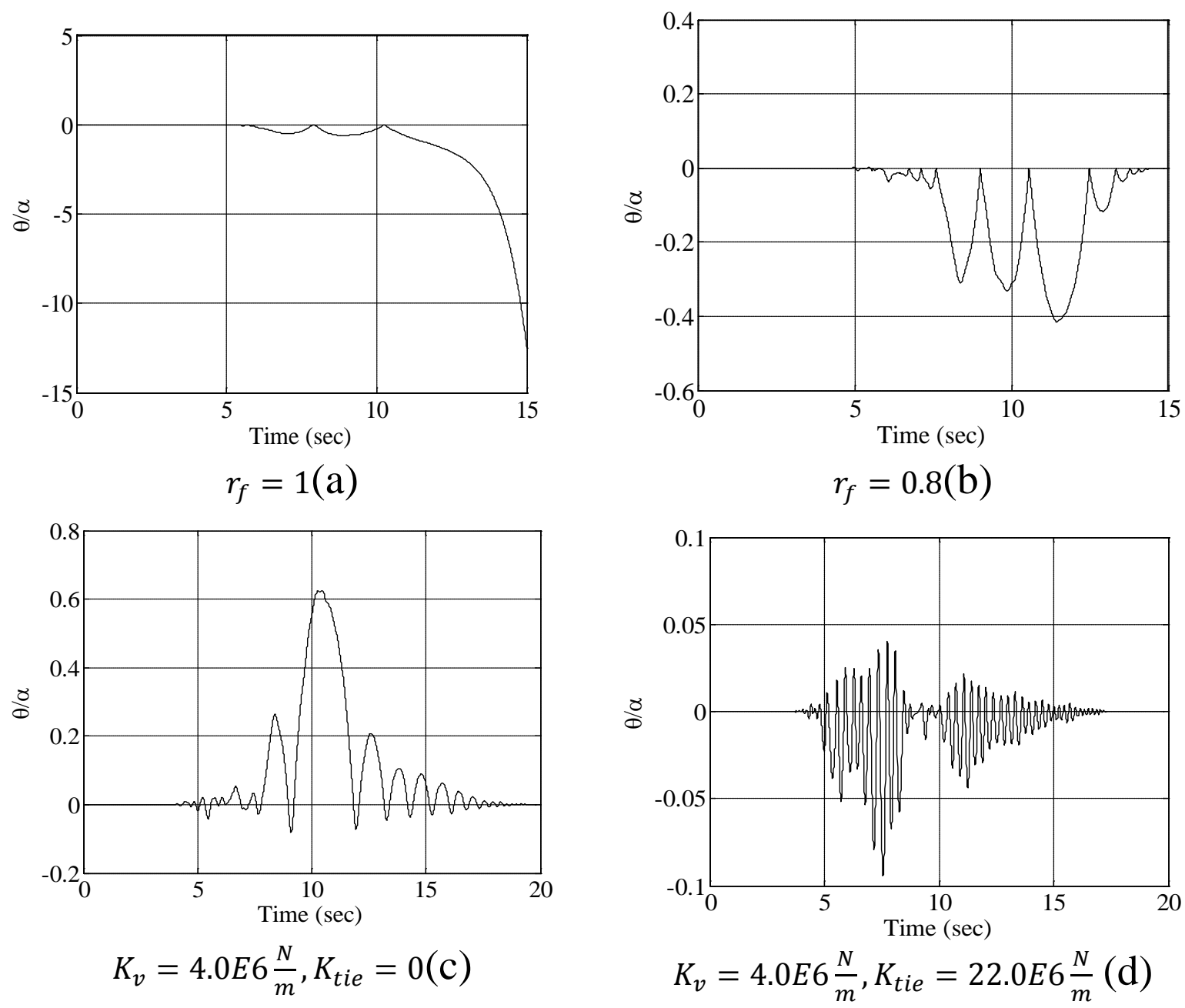

Fig. 11 - Rocking analysis for the façade of Beata Vergine Annunziata church: rebound effect by transverse walls without additional damping (a), with additional damping (b), considering different boundary conditions with only the vault (c) and the vault and a steel tie $\operatorname{rod}(d)$.

Obviously, the analysis presented is valid only if the maximum displacement $\delta_{\mathrm{V} \text {,max }}$ of the vault support can be attained (Fig. 11c):

$$
\delta_{\mathrm{V}, \max }=R_{\mathrm{V}} \sin \vartheta_{\max ,(c)}=700 \cdot \sin (0.63 \cdot 0.05)=22.05 \mathrm{~cm}
$$

which is too high. Nevertheless, if the tie-rod is considered, this value decreases to (Fig. 11d):

$$
\delta_{\mathrm{V}, \max }=R_{\mathrm{V}} \sin \vartheta_{\max ,(d)}=700 \cdot \sin (0.095 \cdot 0.05)=3.25 \mathrm{~cm}
$$

To regard this value as attainable, the vault made up only by traditional masonry is likely to be insufficient and some strengthening (e.g. with an overlay made of an inorganic matrices and a net) are required. Experimental results on masonry vaults, with and without strengthening, would provide the correct data to modify the proposed software so that after a given value of the vault horizontal displacement, the stiffness $K_{v}$ is set to zero. 


\subsection{Considerations on the effect of the additional stiffness $K$}

The benefit of introducing an additional stiffness $K$ in rocking analysis, namely the reduction of amplitude ratios to admissible values, emerges whenever the term depending on $K$ in Eq. (1) numerically overcomes the term depending on the ground acceleration $\ddot{u}_{g}$. The response is not influenced by the mass value if $K=0$; indeed, all the remaining terms of Eq. (1) depend on the mass $m$. Nevertheless, if $K \neq 0$ the response over time depends on the mass.

Let us consider the 175-tons façade analyzed in $\S 4.2$, assuming a two-sided motion. The maximum amplitude ratio is 0.60 if $K=0$ (Fig. 12a).If $K=100 \mathrm{~N} / \mathrm{m}$, basically no change occurs (Fig. 12b).

$\mathbf{K}=\mathbf{0} \mathbf{N} / \mathbf{m}$ (a)

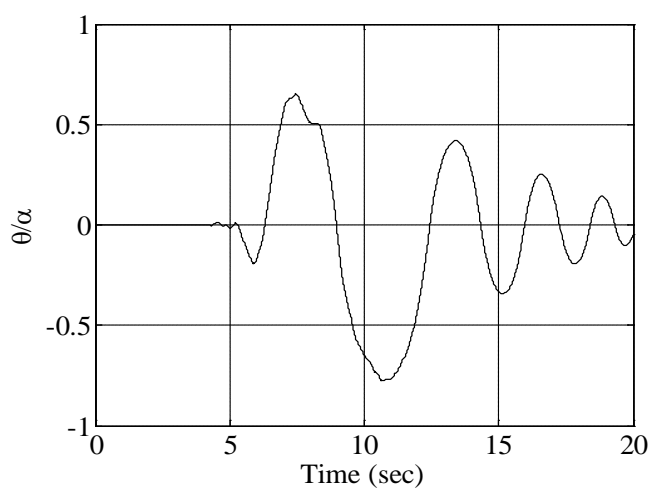

$\mathrm{K}=1 \mathrm{E} 6 \mathrm{~N} / \mathrm{m}$ (c)

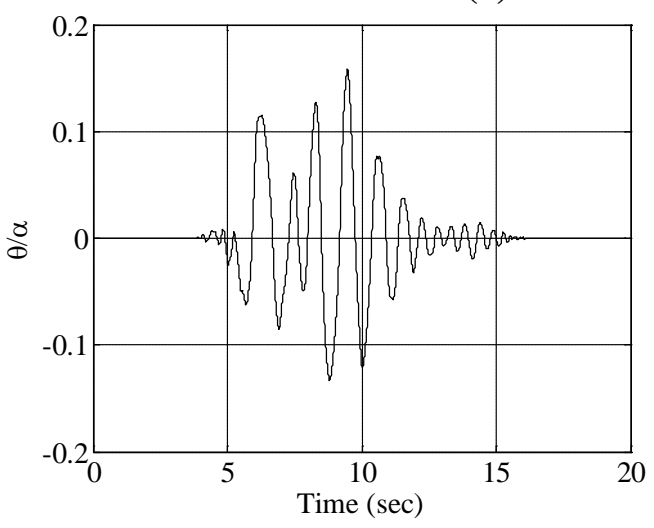

$\mathrm{K}=\mathbf{1 0 0} \mathbf{N} / \mathbf{m}(\mathbf{b})$
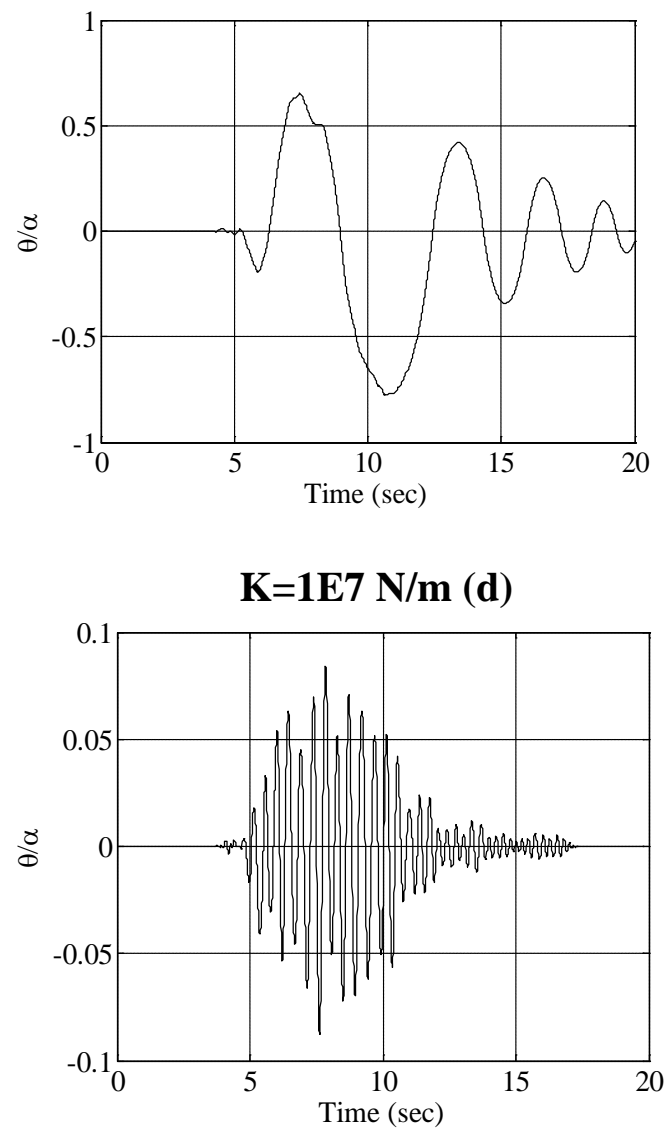

Fig. 12: Façade of BeataVergine Annunziata (two-sided motion) with different $K$ values at the top

Although the response is already in a safe domain, a larger $K$ has to be assumed to obtain a lower amplitude ratio. In addition, similarly to the restoring term depending on the selfweight, the contribution of the $K$ term in the equation of motion might not be conservative(overturning effect) depending on the type of action involved. Thus, not always the effect of any $K>0$ decreases the amplitude ratio. A stiffness of $1 \mathrm{E} 6 \mathrm{~N} / \mathrm{m}$ is needed to obtain a reduction by $75 \%$ of the amplitude ratio (Fig. 12c), and a reduction by $85 \%$ for $K=1 \mathrm{E} 7 \mathrm{~N} / \mathrm{m}$ (Fig. 12d). A value of $1 \mathrm{E} 7 \mathrm{~N} / \mathrm{m}$ corresponds, for instance, to a steel tie-rod with $14 \mathrm{~mm}$ diameter and $3 \mathrm{~m}$ length. The one-sided case is generally not efficient, as occurs in façades restrained by transverse walls [26]. Thus, in the non-linear case, assuming a finite value for $K^{+}$and a zero value for $K^{-}$or vice versa could result in overturning. 
Eq. (1) may be written as follows, by substituting $I_{0}=\frac{4}{3} \mathrm{~m}\left(\mathrm{~h}^{2}+\mathrm{b}^{2}\right)=\frac{4}{3} \mathrm{mR}^{2}$ :

$$
\ddot{\vartheta}+W S T A B+K S T A B+E D E S T=0
$$

where the stabilizing terms are:

$$
\begin{gathered}
W S T A B=\operatorname{sgn}(\vartheta) \frac{m g R}{I_{0}} \sin (\alpha-\operatorname{sgn}(\vartheta) \vartheta)=\operatorname{sgn}(\vartheta) \frac{3}{4} \frac{g}{\mathrm{R}} \sin (\alpha-\operatorname{sgn}(\vartheta) \vartheta) \\
K S T A B=+\operatorname{sgn}(\vartheta) 4 \frac{K R^{2}}{I_{0}} \cos (\alpha-\operatorname{sgn}(\vartheta) \vartheta)[\sin \alpha-\sin (\alpha-\operatorname{sgn}(\vartheta) \vartheta)]= \\
\operatorname{sgn}(\vartheta) \frac{3 K}{\mathrm{~m}} \cos (\alpha-\operatorname{sgn}(\vartheta) \vartheta)[\sin \alpha-\sin (\alpha-\operatorname{sgn}(\vartheta) \vartheta)]
\end{gathered}
$$

and the term with destabilizing effect is :

$$
E D E S T=-\frac{m g R}{I_{0}} \ddot{u}_{g} \cos (\alpha-\operatorname{sgn}(\vartheta) \vartheta)=-\frac{3}{4} \frac{g}{\mathrm{R}} \ddot{u}_{g} \cos (\alpha-\operatorname{sgn}(\vartheta) \vartheta)
$$

If the value of $m$ is high, the term $K S T A B$ might be too low to provide a reduction of the amplitude ratio obtained with $K=0$. Also, this term should overcome or at least be similar to the contribution given by the term depending on the self-weight. Therefore, the larger the wall mass, the larger the $K$. Fig. 13 shows the behavior of the three terms varying the rotation of $\vartheta$, assumed for the façade $\alpha=0.05 \mathrm{rad}, R=5.04 \mathrm{~m}$ and a self weight of $1775 \mathrm{kN}$. In EDEST a constant acceleration value of $0.5 \mathrm{~g}$ was assumed.
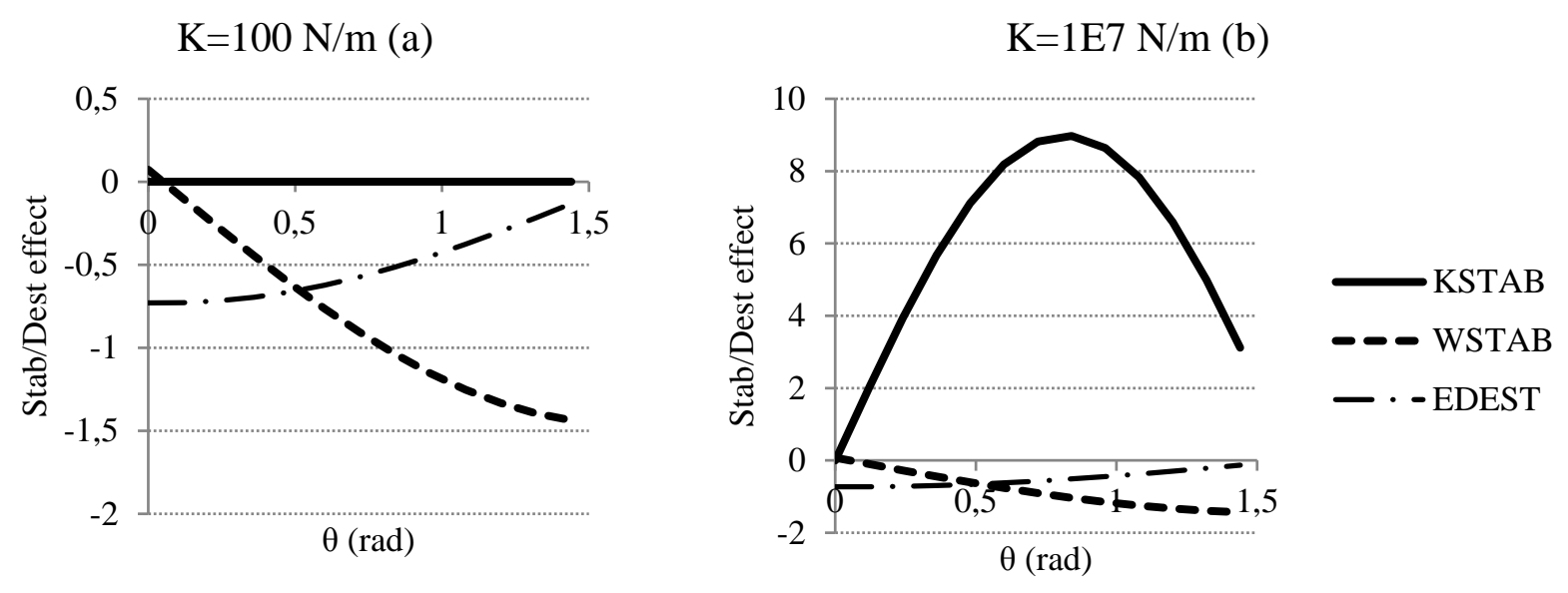

Fig. 13: Stabilizing and destabilizing effect of the terms in the equation of motion, for two values of the additional horizontal stiffness Kof 100N/m (a) and 1E7 N/m (b)

The effect of the spring vanishes if $K$ is low, for example $100 \mathrm{~N} / \mathrm{m}$ (Fig. 13a), while for higher values its contribution is much higher (Fig. 13b). For the case under examination, the check of these terms can provide a first idea on the effectiveness of the strengthening system.

By neglecting the cosine term, which is common to EDEST and to KSTAB, and by noting that the maximum value of $[\sin \alpha-\sin (\alpha-\operatorname{sgn}(\vartheta) \vartheta)]$ is 1 , as general advice, the term $c_{K}=4 K R^{2} / I_{0}$ should be one or two orders of magnitude greater than the square of the frequency parameter $p^{2}=c_{E}=m g R / I_{0}$. Indeed, in the presented cases if $K=100 \mathrm{~N} / \mathrm{m}$, $c_{K}=0.002$ and $c_{E}=1.46$, whereas if $K=1 E 7 \mathrm{~N} / \mathrm{m}, c_{K}=167.7$ and $c_{E}=1.46$.

The evaluation of the global stiffness of the dynamic system shown in Fig. 9 is also useful to determine the effectiveness of horizontal restrainers. By following the procedure adopted by 
Makris \& Vassiliou for vertical restrainers applied on a rocking frame [36], the rotationdependent restoring moment is:

$$
M_{r}(\vartheta)=m g R \sin (\alpha-\vartheta)+4 K R^{2} \cos (\alpha-\vartheta)[\sin \alpha-\sin (\alpha-\vartheta)]
$$

assuming that $\vartheta(t)>0$, without loss of generality. Substitutingsin $(\alpha-\vartheta)=\sin \alpha \cos \vartheta-$ $\cos \alpha \sin \vartheta$ and $\cos (\alpha-\vartheta)=\cos \alpha \cos \vartheta+\sin \alpha \sin \vartheta$ and rearraging terms, Eq. (14) becomes:

$$
\begin{aligned}
M_{r}(\vartheta)=m g R & \{\sin \alpha \cos \vartheta-\cos \alpha \sin \vartheta \\
& +\frac{4 K R}{m g}[\sin \alpha \cos \alpha \cos \vartheta+ \\
& \left.\left.-\sin \alpha \cos \alpha \cos 2 \vartheta+\cos ^{2} \alpha \sin \vartheta \cos \vartheta+\sin ^{2} \alpha \sin \vartheta-\sin ^{2} \alpha \sin \vartheta \cos \vartheta\right]\right\}
\end{aligned}
$$

Assuming small rotations and linearizing to first order terms, $\sin \vartheta \cong \vartheta$ and $\cos \vartheta \cong 1$, one has:

$$
M_{r}(\vartheta)=m g R \sin \alpha\left[1-\vartheta\left(\cot \alpha-\frac{4 K R}{m g} \cot \alpha \cos \alpha\right)\right]
$$

and the dimensionless restoring moment can be written:

$$
\frac{M_{r}(\vartheta)}{m g R}=\sin \alpha\left[1-\vartheta\left(\cot \alpha-\frac{4 K R}{m g} \cot \alpha \cos \alpha\right)\right]
$$

The factor of the rotation angle $\vartheta$ in Eq. (17) is the system global stiffness. The block without restrainer has negative stiffness (Fig. 1), which increases becoming positive if

$$
\frac{4 K R}{m g}>\frac{1}{\cos \alpha}
$$

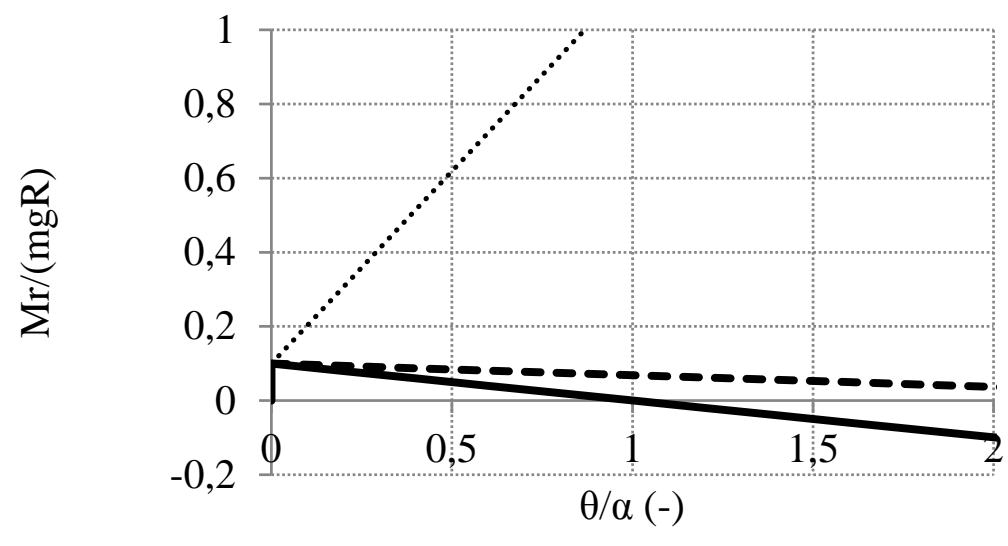

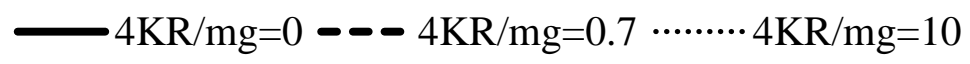

Fig. 14: Moment-rotation diagram for different values of the dimensionless stiffness $\frac{4 K R}{\mathrm{mg}}$ of the horizontal restrainer ( $\alpha=0.10 \mathrm{rad}$ and $R=5 \mathrm{~m}$ ) 
With respect to the role of vertical restrainer studied by Makris \& Vassiliou [36], for which the condition for the stiffness to be positive depends on $\frac{E A}{m g}=\frac{K L}{m g}$ and on the slenderness $\alpha$, here the effectiveness of the horizontal restrainer depends also upon the semi-diagonal $R$. With the same $K$, larger blocks undergo greater enhancement. Fig. 14 plots Eq. (17) for $R=5 \mathrm{~m}$ and $\alpha=0.10$ rad: by increasing the value of the dimensionless stiffness $\frac{4 K R}{\mathrm{mg}}$, the slope of the restoring moment changes from negative to positive. The linearized expression of $M_{r}(\vartheta)$ in Eq. (16) gives results different from those of the non-linearized one by about $0.5 \%$.

\subsection{Systemic analysis for different spectra and recorded earthquakes}

The aim of this final section is to investigate the role of boundary conditions, represented by $K$, in the dynamic response of the block, based on the Housner formulation.Walls with $R=$ $1.5,2,2.5,3,3.5,7,10 \mathrm{~m}$ and $\alpha=0.05,0.10,0.15,0.25$ (28 blocks types) for the same acceleration time-histories used in $\S 3.3$ (PGA ranging between $0.055 \mathrm{~g}$ and $1.345 \mathrm{~g}$ ), for $K=0$, $1 \mathrm{E} 3,1 \mathrm{E} 4,1 \mathrm{E} 6 \mathrm{~N} / \mathrm{m}$ have been examined, leading to a total of 560 cases investigated. The width of all walls is fixed and assumed $3 \mathrm{~m}$, while the specific weight is $\gamma=18 \mathrm{kN} / \mathrm{m}^{3}$. In Table 2 some values of $K$ for a steel tie-rod with length equal to $3 \mathrm{~m}$ and variable diameter are listed. Obviously, also longer tie-rods are possible in monumental structures.

\begin{tabular}{c|c}
$\mathrm{d}(\mathrm{mm})$ & $K(\mathrm{~N} / \mathrm{m})$ \\
\hline 2 & $2.2 \mathrm{E}+05$ \\
\hline 5 & $1.4 \mathrm{E}+06$ \\
\hline 10 & $5.5 \mathrm{E}+06$ \\
\hline 20 & $2.2 \mathrm{E}+07$ \\
\hline 30 & $4.9 \mathrm{E}+07$ \\
\hline 40 & $8.8 \mathrm{E}+07$ \\
\hline 50 & $1.4 \mathrm{E}+08$ \\
\hline
\end{tabular}

Table 2 - Kvalues of steel tie-rod with length of $3 \mathrm{~m}$ and variable diameter

The following comments can be made from the results of the rocking response of the analyzed blocks and acceleration time-histories displayed in Fig. 15 and Fig. 16as an example. For $\alpha \geq 0.10 \mathrm{rad}$,the blocks survive all the acceleration time-histories except Cape Mendocino (Fig. 16a). Also in the kinematic analysis, as will be discussed next, if $\alpha \geq$ $0.10 \mathrm{rad}$ the ultimate limit state is not reached, so no collapse occurs.

Furthermore, it is noteworthy to compare these results with the outcomes from the kinematic non-linear approach proposed by the Italian code. In this case, obviously, for all $K$ values the acceleration that triggers motion $a_{0}^{*}$ does not change, as the spring at $u=0$ is inactive.

The inconsistencies between the current normative approach and the dynamic analysis can be recognized only for $K=1000 \mathrm{~N} / \mathrm{m}$ and $\alpha=0.05 \mathrm{rad}$; indeed, for higher values of stiffness ( $K \geq 1 \mathrm{E} 4 \mathrm{~N} / \mathrm{m}$ ) and slenderness ratio ( $\alpha \geq 0.10 \mathrm{rad}$ ), no collapse occurs either in the kinematic or in the dynamic analysis. In the 100 analysis performed assuming $K=1000 \mathrm{~N} / \mathrm{m}$ and $\alpha=0.05$ rad, there are 8 inconsistencies, namely cases which are safe with rocking analysis and unsafe with the normative approach. 14blocks collapse with the code approach, therefore $8 / 14=57 \%$ of the blocks that overturn in this procedure survive in the rocking analysis (Fig. 17). Consequently, the code approach is found to be again conservative. For $K=1 \mathrm{kN} / \mathrm{m}$ and 
$\alpha=0.05 \mathrm{rad}$, the acceleration-displacement curve is almost linear, and the ultimate displacement capacity increases (Fig. 18a).

For higher values of $K$, e.g. $K=10000 \mathrm{~N} / \mathrm{m}$, the shape of the curve is less linear for lower $R$ (Fig. 18b). This occurs since the restoring effect is more pronounced as the self-weight is lower for lower $R$. The same consideration has been made for the rocking analysis, where the benefit of introducing $K$ is effective for stiffness values larger than a threshold value.

(a)

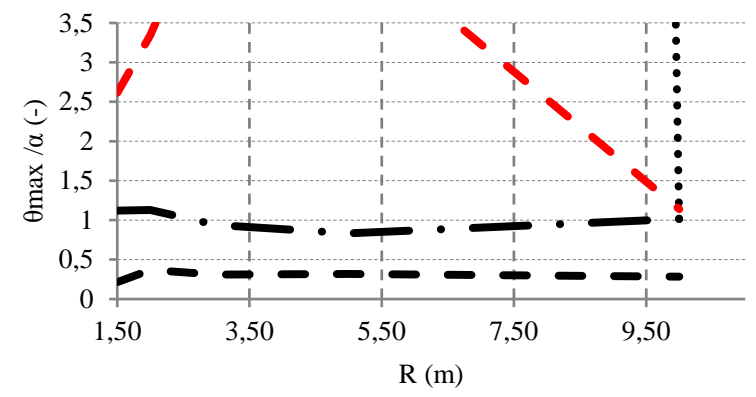

$\cdots .$. C_MEND K=1E3 N/m - - C_MEND K=1E4 N/m
- C_MEND K=1E5 N/m - C_MEND K=1E6 N/m

(c)

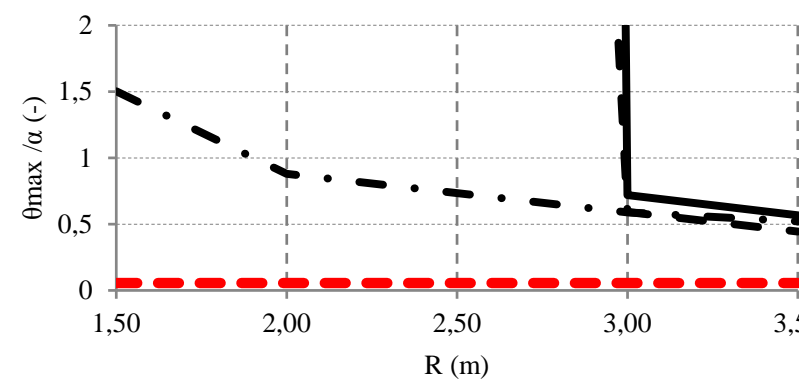

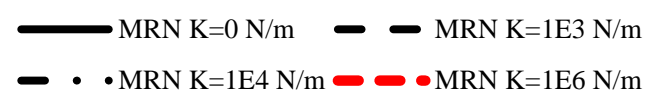

(b)

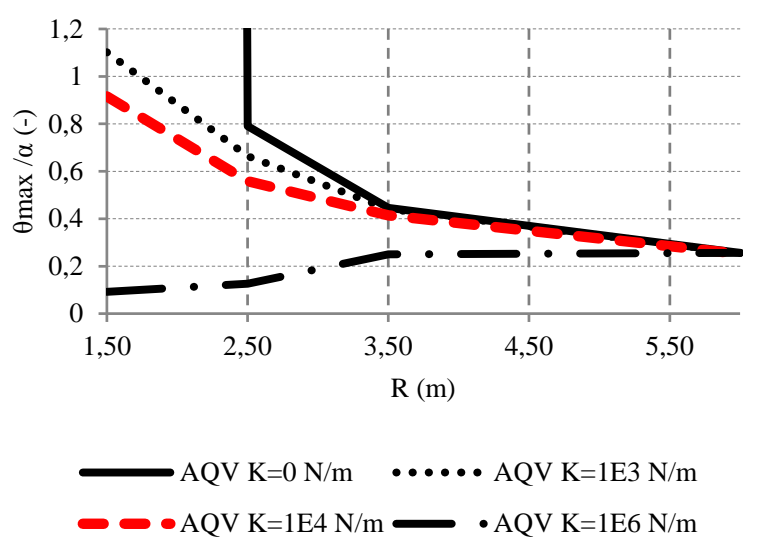

(d)

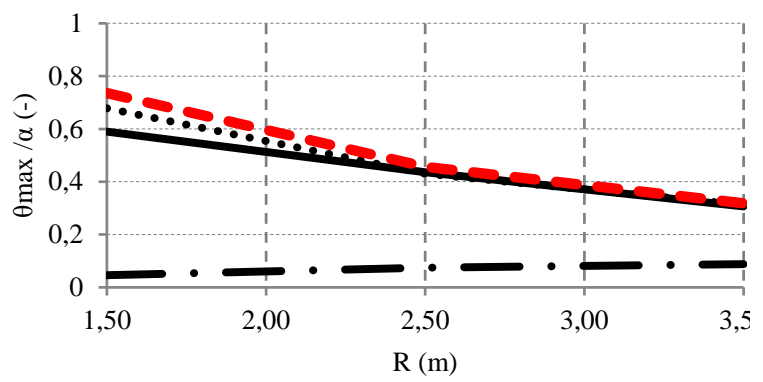

$\longrightarrow$ MOG0 K=0 N/m $\cdots \cdots \cdot$ MOG K=1E3 N/m
$\bullet \bullet$ MOG K=1E4 N/m MOG K=1E6 N/m

Fig. 15: Rocking analysis results ( $\alpha=0.05$ rad): Cape Mendocino (a), L'Aquila (b), Mirandola (c) and Moglia (d) records

Finally, it is noticed that the values of $K$ in the present analysis are low for typical steel tierods (Table 2), but they have been considered for comparison purposes between the approaches. For higher values of $K$ in both approaches no collapses occur for these earthquake magnitudes, while again different responses will be obtained for stronger earthquakes. 
(a)

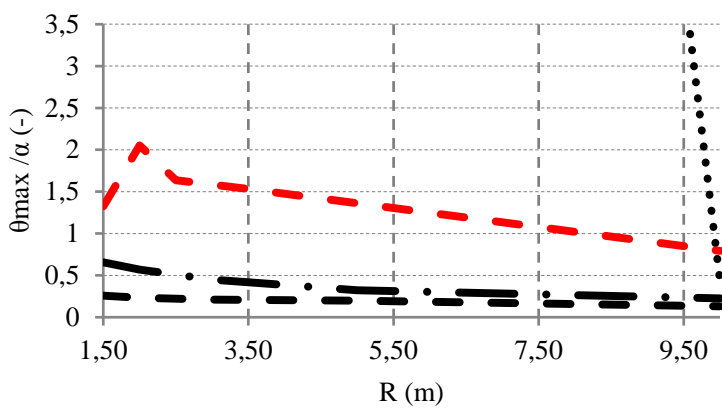

•... C_MEND K=1E3 N/m $\longrightarrow$ C C_MEND K=1E4 N/m

-C_MEND K=1E5 N/m - C C_MEND K=1E6 N/m

(c)

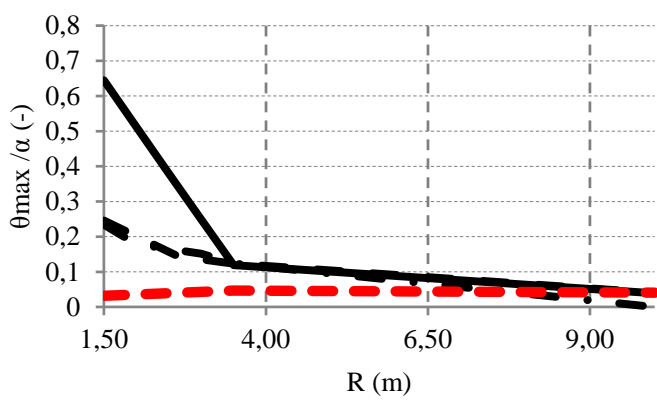

$\longrightarrow$ MRN K=0 N/m - MRN K=1E3 N/m

- $\cdot$ MRN K=1E4 N/m $\rightarrow \bullet$ MRN K=1E6 N/m (b)

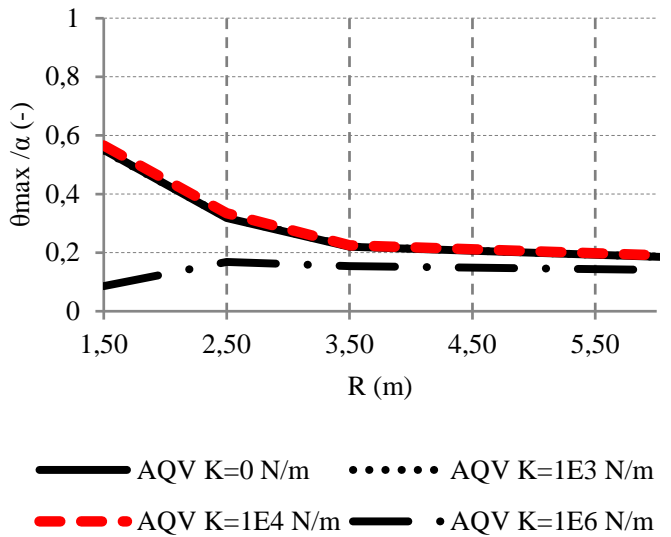

(d)
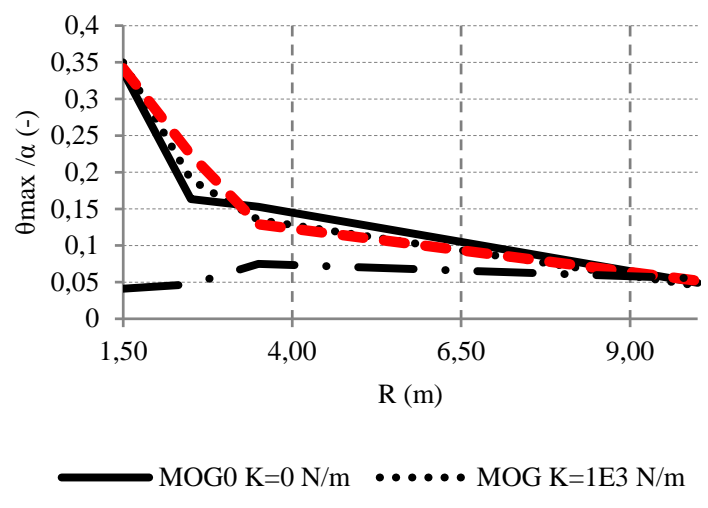

$\bullet \cdot \mathrm{MOG}$ K=1E4 N/m $\longrightarrow$ MOG K=1E6 N/m

Fig. 16: Rocking analysis results ( $\alpha=0.10 \mathrm{rad})$ : Cape Mendocino (a), L'Aquila (b), Mirandola (c) and Moglia (d) records

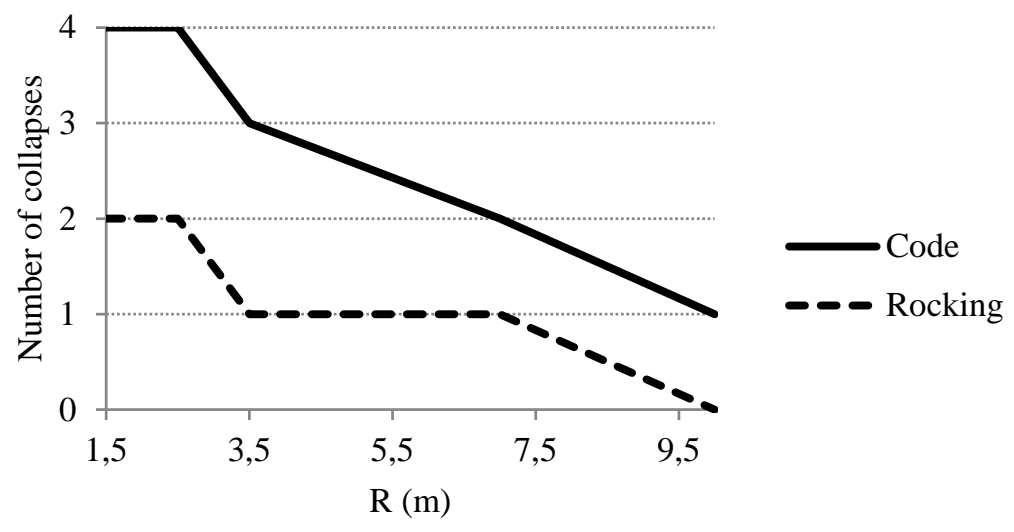

Fig. 17: Comparison between the code approach and the rocking analysis for the case $K=1000 \mathrm{~N} / \mathrm{m}$ and $\alpha=0.05 \mathrm{rad}$ 
(a)

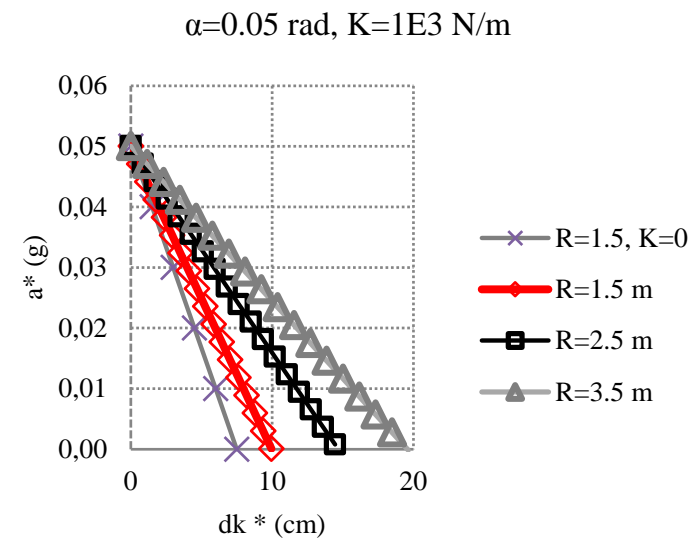

(b)

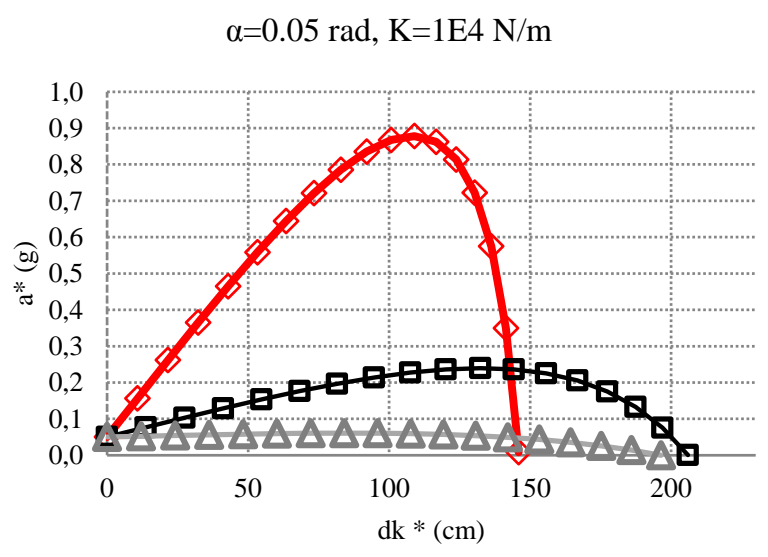

Fig. 18: Kinematic curves for the equivalent single DOF oscillator: $K=1 \mathrm{E} 3 \mathrm{~N} / \mathrm{m}$ (a) and $\mathrm{K}=1 \mathrm{E} 4 \mathrm{~N} / \mathrm{m}$ (b)

\section{CONCLUSIONS}

This paper investigates the rocking analysis of masonry walls. Two aspects are discussed: the effect of different boundary conditions applied to the Housner block, such as strengthening devices or transverse walls/vaults, and the comparison with the kinematic approach proposed by the Italian code. The analysis of an altar, which most likely rocked without collapsing during the Emilia Romagna 2012 earthquake, is performed, showing that the code approach is conservative. Similar results have been obtained from a systemic analysis of masonry walls having different sizes and slenderness. The method proposed by the Italian code was conservative in 54\% of the cases when collapse occurred.

In addition, the effect of different boundary conditions represented by a horizontal spring with stiffness $K$ has beenconsidered. The equation proposed by Housner has been updated by taking into account this additional term. A non-linear case study of a church façade connected to a vault and a steel tie rod has been analyzed by considering the rebound effect caused by transverse walls. For the latter approach, the response is very sensitive to the additional damping, which is difficult to determine. In the proposed method, the equivalent stiffness of the vault is considered as a finite $K$ value. Thus, if the stiffness is determined so as to account for the actual boundary conditions of the wall, the proposed method can provide realistic results. A check for a quick assessment of the effectiveness of the strengthening measure has been provided, in order to have a reference value of the needed stiffness. Indeed, the effectiveness of horizontal restrainers is stronger for higher value of stiffness $K$ and larger block size. The lateral stiffness of the systems changes from negative - for the freestanding block - to positive for horizontally restrained block with $K$ value over the specified limit. Finally, a systemic analysis with a finite value of $K$ at the top of the wall demonstrated that the code kinematic approach was conservative in $57 \%$ of cases.

\section{REFERENCES}

[1] Consiglio Superiore LL. PP., Linee Guida per la valutazione e riduzione del rischio sismico del patrimonio culturale con riferimento alle norme tecniche per le costruzioni: Testo allegato al parere n. 66, 2006. 
[2] M. Andreini, A. De Falco, L. Giresini, M. Sassu, Mechanical Characterization of Masonry Walls with Chaotic Texture: Procedures and Results of In-Situ Tests, Int. Journal of Arch. Heritage 8 (2014) 367-407.

[3] M. Andreini, A. De Falco, L. Giresini, M. Sassu, Structural damage in the cities of Reggiolo and Carpi after the earthquake on May 2012 in Emilia Romagna, Bulletin of Earthquake Engineering (to be published) (2014).

[4] Nuove Norme Tecniche per le Costruzioni, D.M. 14/01/2008, approvazione delle nuove norme tecniche per le costruzioni, G. U. della Repubblica Italiana, n. 29 del 4 febbraio 2008 Supplemento Ordinario n. 30, 2008.

[5] N. Makris, A half-century of rocking isolation, Earthquakes and Structures 7 (2014) 1187-1221.

[6] N. Makris, The Role of the Rotational Inertia on the Seismic Resistance of Free-Standing Rocking Columns and Articulated Frames, Bulletin of the Seismological Society of America 104 (2014) 2226-2239.

[7] G.W. Housner, The behavior of inverted pendulum structures during earthquakes, Bulletin of the Seismological Society of America 53 (1963) 403-417.

[8] N. Makris, Y. Roussos, Rocking Response and Overturning of Equipment Under Horizontal Pulse-Type Motions: Report PEER 1998/05, 1998.

[9] M. Campillo, J.C. Gariel, K. Aki, F.J. Sanchez-Sesma, Destructive Strong Ground Motion in Mexico City: Source, Path and Site Effects during the great 1985 Michoacan Earthquake, Bull. Seism. Soc. Am. 79 (1989) 1718-1735.

[10] W.D. Iwan, X.D. Chen, Important near field ground motion data from the Landers earthquake, Proc. 10th European Conf. Earthquake Engrg. Vienna (1994).

[11] K.T. Doherty, An investigation of the weak links in the seismic load path of unreinforced masonry buildings. Ph.D., Adelaide, 2000.

[12] O. Al Shawa, G. de Felice, A. Mauro, L. Sorrentino, Out-of-plane seismic behaviour of rocking masonry walls, Earthquake Engng Struct. Dyn. 41 (2012) 949-968.

[13] L. Sorrentino, O. AlShawa, L.D. Decanini, The relevance of energy damping in unreinforced masonry rocking mechanisms. Experimental and analytic investigations, Bulletin of Earthquake Engineering 9 (2011) 1-26.

[14] L. Sorrentino, Dinamica di muri sollecitati fuori dal piano come sistemi di corpi rigidi. Ph.D., Roma, 2003.

[15] G. De Felice, R. Giannini, Out-of-plane seismic resistance of masonry walls, Journal of Earthquake Engineering 5 (2001) 253-271.

[16] F. Peña, F. Prieto, P.B. Lourenço, A. Campos Costa, J.V. Lemos, On the dynamics of rocking motion of single rigid-block structures, Earthquake Engng Struct. Dyn. 36 (2007) 2383-2399.

[17] G. de Felice, A. Mauro, On overturning of the façade in churches with single nave: some case studies from L’Aquila, Italy, 2009 earthquake, Advanced material research 133-134 (2010) 807-812.

[18] P.R. Lipscombe, S. Pellegrino, Free rocking of prismatic blocks, Journal of Structural Engineering 119 (1993) 1387-1410.

[19] N. Makris, M.F. Vassiliou, Planar rocking response and stability analysis of an array of free-standing columns capped with a freely supported rigid beam, Earthquake Engng Struct. Dyn. 42 (2013) 431-449.

[20] M.J. DeJong, E.G. Dimitrakopoulos, Dynamically equivalent rocking structures, Earthquake Engng Struct. Dyn. 43 (2014) 1543-1563.

[21] M. Aslam, W.G. Godden, D.T. Scalise, Rocking and Overturning Response of Rigid Bodies to Earthquake Motions, Lawrence Berkeley National Laboratory Berkeley, Calif. Dept. of Energy, Lawrence Berkeley Laboratory, LBL (1978) 86 p. 
[22] A. Costa, Seismic Assessment of the Out-of-Plane Performance of Traditional Stone Masonry Walls. Ph.D., 2012.

[23] N. Makris, D. Kostantinidis, The Rocking Spectrum and the Shortcomings of Design Guidelines: PEER Report 2001/07, 2001.

[24] I. The MathWorks, MATLAB and Statistics Toolbox, Natick, Massachusetts, United States.

[25] S.C. Chapra, R.P. Canale, Numerical Methods for Engineers, 2010.

[26] L. Sorrentino, S. Kunnath, G. Monti, G. Scalora, Seismically induced one-sided rocking response of unreinforced masonry façades, Engineering Structures 30 (2008) 2140-2153.

[27] Y. Ishiyama, Motions of rigid bodies and criteria for overturning by earthquake excitations, Earthquake Engineering and Structural Dynamics 10 (1982) 635-650.

[28] Approvazione delle Nuove Norme Tecniche per le Costruzioni: NTC2008, in: Gazzetta Ufficiale della Repubblica Italiana n. 29, February, 28th 2008, Supplemento Ordinario n. 30, 2008.

[29] N. Makris, G. Kampas, The Engineering Merit of the "Effective Period" of Bilinear Isolation Systems, Earthquakes and Structures 4 (2013) 397-428.

[30] A. Giuffrè, Seismic damage in historic town centers and attenuation criteria, Ann Geofis 38 (1995) 837-843.

[31] Eurocode 6: Design of masonry structures - Part 1-1: General rules for reinforced and unreinforced masonry structures, The European Union Per Regulation 305/2011, Directive 98/34/EC, Directive 2004/18/EC.

[32] Accelerograms Database of seismic shocks on May, 29th2012, Emilia Romagna region (Italy). Department of Italian Civil Protection, 2012, Information on http://www.mot1.it/randownload/EN/index.php

[33] USGS, Peer Strong Motion Database Record Processed By Pacific Engineering, 2014.

[34] L. Sorrentino, R. Masiani, L.D. Decanini, Overturning of rocking rigid bodies under transient ground motions, Structural Engineering and Mechanics 22 (2006) 293-310.

[35] L. Giresini, C. Butenweg, M. Andreini, A. De Falco, M. Sassu, Numerical Calibration Of A Macro-Element For Vaulted Systems In Historic Churches, Proceedings of the 9th International Conference on Structural Analysis of Historical Constructions, October 14th-17th (2014).

[36] N. Makris, M.F. Vassiliou, Dynamics of the Rocking Frame with Vertical Restrainers, J. Struct. Eng. (2014) 4014245. 